Roles of Family Stress, Maltreatment, and Affect Regulation Difficulties on Adolescent Mental Health During COVID-19

Stephanie G. Craig $\mathrm{PhD}^{1^{*}}$, Christina L. Robillard $\mathrm{MSc}^{2}$, Brianna J. Turner $\mathrm{PhD}^{2}$, \& Megan E. Ames $\mathrm{PhD}^{2}$

1. York University, 5021 Dahdaleh Building, 4700 Keele St, Toronto, Ontario, Canada, M3J 1P3

2. University of Victoria, A193 Cornett Building, 3800 Finnerty Road, Victoria, BC, Canada V8P5C2

Corresponding Author Contact Details:

Stephanie Craig, Department of Psychology, York University, 4700 Keele St, Toronto, Ontario, Canada, M3J 1P3. E: sgcraig@yorku.ca 


\begin{abstract}
Purpose: This study examines the indirect effect of affect dysregulation and suppression on the associations between family stress from confinement, maltreatment, and adolescent mental health during COVID-19. We examined both adolescent and caregiver perspectives to yield a more well-rounded understanding of these associations. Methods: Using both adolescent $\left(N=809, \mathrm{M}_{\text {age }}\right.$ $=15.66)$ and caregiver $(N=578)$ samples, exposure to physical and psychological maltreatment, family stress from confinement, affect dysregulation, suppression, and youth externalizing and internalizing symptoms were measured in the summer of 2020 , following three months of stay at home orders due to COVID-19. Results: We found that affect dysregulation partially accounted for the associations between family stress and psychological maltreatment on both internalizing and externalizing symptoms for youth and parent report. Suppression partially accounted for the associations between family stress and maltreatment on internalizing and externalizing symptoms in the youth sample, but only for internalizing symptoms in the caregiver sample. Conclusion: Understanding the family predictors of adolescents' mental health concerns, and their underlying mechanisms, affect dysregulation and suppression, can help us target mental health interventions during and following the COVID-19 pandemic.
\end{abstract}

Keywords: Maltreatment; Affect Dysregulation; Suppression; Mental Health; Family Stress 


\section{Roles of Family Stress, Maltreatment, and Affect Regulation Difficulties on Adolescent Mental Health During COVID-19}

The welfare of youth and their families should be a top priority as we navigate the disruptions to daily life caused by the coronavirus disease 2019 (COVID-19) pandemic. Prior to the pandemic, maltreatment was a serious public health problem, with roughly 34 per 1000 adolescents in Canada involved in investigations for some form of maltreatment (e.g., psychological, physical, sexual, and/or neglect; Trocmé, 2010). Although reported incidences of maltreatment to children's aid services have decreased during the pandemic, researchers have cautioned this may be due to reduced access to typical reporting systems rather than a true decline in maltreatment (Cabrera-Hernández et al., 2020). In fact, given that many families are highly stressed and confined at home, there is strong reason to expect marked increases in child maltreatment during the COVID-19 pandemic (Cuartas, 2020). This raises serious concerns about the mental health of the next generation of Canadians, as maltreatment is a robust risk factor of both internalizing (e.g., depression, anxiety) and externalizing (e.g., conduct disorder, oppositional defiant disorder) problems (Cicchetti, 2016; Moretti et al., 2014). Unfortunately, no research has investigated the associations between family stress from confinement, maltreatment, and mental health difficulties among adolescents during COVID-19, nor has research identified the mechanisms by which these associations unfold. The current study addressed this gap by examining whether affect regulation difficulties (e.g., affect dysregulation and suppression) account for the indirect effect in the associations between family stress from confinement and maltreatment on mental health problems in youth during the pandemic. We examined both adolescent and caregiver perspectives to yield a more well-rounded understanding of these associations. We hope this research informs interventions to reduce youth's mental health 
problems during and following the pandemic.

\section{Maltreatment, Affect Regulation Difficulties, and Mental Health}

One way that maltreatment affects adolescents' mental health is through disruptions to their ability to regulate and/or tolerate negative emotional experiences, a set of abilities collectively termed affect regulation (Thompson, 2019). Two potential affect regulation outcomes of maltreatment include affect dysregulation (i.e., difficulty regulating and/or tolerating negative emotions; Cicchetti, 2016) and suppression (i.e., tendency to avoid or suppress negative emotions; Sistad et al., 2021). From an attachment perspective, affect regulation develops in the context of dynamic interactions between adolescents and their caregivers (Bowlby, 1973). Notably, a caregiver's ability to recognize and validate their youth's emotional experience, and thus provide a secure base, is thought to form the foundation of affect regulation in adolescents (Stevens, 2014). Adolescents who can effectively regulate their affect are better equipped to manage difficult situations and stressors, thereby buffering against mental health difficulties (see Troy \& Mauss, 2011, for a review). If caregivers are unable to provide sensitive responses to an adolescent's distress, however, youth may try to cope on their own, possibly resulting in affect dysregulation and/or suppression (Gross \& Cassidy, 2019). Maltreated adolescents are at elevated risk for affect dysregulation (see Gruhn \& Compas, 2020, for a meta-analytic review), in part due to the absence of sensitive interactions with caregivers (Kim \& Cicchetti, 2010). Indeed, affect dysregulation has been shown to mediate the association between maltreatment and mental health problems in children, adolescents, and adults (Kim \& Cicchetti, 2010; Moretti \& Craig, 2013). Moreover, when maltreatment occurs from a primary caregiver, adolescents can be left feeling intimidated by the very attachment figure who is supposed to protect and support them (Kim \& Cicchetti, 2010); this dramatically elevates their 
risk of suppression as they can learn that emotional outbursts may lead to more physical or emotional pain. Although suppression has been shown to mediate maltreatment and perceived stress in adults (e.g., Hong et al., 2018), its role in an indirect pathway to mental health difficulties in adolescents has been less explored.

The associations between maltreatment, affect regulation difficulties, and mental health problems in adolescents may be particularly pronounced in the context of COVID-19. The reasons for this are three-fold. First, public health responses to the pandemic (e.g., self-isolation, social distancing) have limited the extent to which adolescents and caregivers can leave their household. Being confined in the home, especially under periods of stress, can exacerbate conflict and prevent family members from getting respite from a potentially tense environment. Moreover, the loss of daily routines and increased contact between family members may highlight normative developmental differences between adolescents and adults, such as differences in sleep or work schedules and leisure activities (e.g., screen time). These conflicting lifestyles may generate additional conflict, while putting pressure on caregivers to be the primary or sole source of regulation for youth. In turn, this may render caregivers more likely to use coercive, or punitive strategies to police their adolescents to meet their school and personal obligations (see Stith et al., 2009). Second, the COVID-19 pandemic may represent a "double hit" for adolescents; not only are they experiencing elevated overall stress from the pandemic, they are also facing increased family stress from being confined in their homes. This may undermine their ability to regulate their affect, as the pandemic presents stress beyond their developmental capacity to manage. Third, for many Canadian adolescents, social interactions with individuals outside of the home have become severely restricted, which is incongruent with adolescents' need for autonomy. As many adolescents rely on teachers, school counsellors, 
peers, and romantic partners as sources of support (Collins \& Laursen, 2004; Levitt et al., 1993), barriers to accessing these supports under conditions of maltreatment and family stress may exacerbate affect regulation difficulties and mental health problems.

\section{Integrating Caregiver and Adolescent Perspectives}

To date, research has only investigated the associations between maltreatment, affect regulation difficulties, and mental health challenges through reports from a single perspective, either of adolescents themselves or their caregivers (Hong et al., 2018; Kim \& Cicchetti, 2010; Moretti \& Craig, 2013). Most research on affect regulation in adolescents has relied on youth self-report (e.g., Moretti \& Craig, 2013). Yet, adolescents with affect regulation difficulties may struggle to report on their emotional experiences, and thus, examining both caregiver and adolescent samples may provide a more well-rounded understanding of the associations between maltreatment, affect regulation difficulties, and mental health problems. In parallel, most research on the association between family stress during COVID-19 and adolescent mental health has relied on caregiver self-report (e.g., Spinelli et al., 2020; Brooks et al., 2020). That said, given that caregivers' reports on family stress may be biased by their own perceived stress related to health, financial stress, and working from home, examining adolescent perspectives may provide a more comprehensive understanding of this association. Furthermore, caregivers and adolescents may have unique and complementary strengths in reporting on different symptom domains. For example, one study found that parents were more reliable in reporting on their youth's presenting mental health issues, while adolescents were more reliable in reporting on family and environmental problems (Hawley \& Weisz, 2003). Adolescents have been found to both overestimate (Rescorla et al., 2013) and underestimate (Salbach-Andrae et al., 2009) their mental problems. It is also possible that parents perceive their own policing of youth's behavior 
via yelling, intimidation, and threats to be normative, while youth may experience these behaviors as harmful. In sum, neither caregivers nor adolescent report are infallible. Research that considers both caregivers' and adolescents' perspectives can thus provide a more wellrounded understanding of the associations between family stress from confinement, maltreatment, affect regulation difficulties, and adolescents' mental health difficulties.

\section{The Present Study}

Although the associations between maltreatment, affect dysregulation, and mental health problems are well-delineated, little to no research has examined whether similar models can be identified across adolescent and caregiver reports or examined these associations during the COVID-19 pandemic. To our knowledge, the current study was also the first to examine how family stress from confinement during the COVID-19 pandemic directly and indirectly relates to maltreatment and adolescents' mental health problems using both adolescent and caregiver samples. Further, research in adolescents on whether suppression has a similar indirect effect in the associations between maltreatment and psychopathology as affect dysregulation is limited. Accordingly, the present study used reports from large samples of Canadian adolescents and caregivers to investigate whether affect regulation difficulties has an indirect effect in the associations between family stress from confinement and maltreatment on adolescent mental health problems during COVID-19. We had three primary hypotheses. We anticipated a positive association between adolescent- and caregiver-reported family stress from confinement and maltreatment (Hypothesis 1; Stith et al., 2009). Consistent with past research (Cicchetti, 2016; Moretti et al., 2014; Moretti \& Craig, 2013), we also hypothesized direct paths between family stress from confinement to maltreatment to both adolescent internalizing and externalizing symptoms (Hypothesis 2). Third, in line with previous work (Kim \& Cicchetti, 2010; Moretti \& 
Craig, 2013), we hypothesized that the direct paths linking family stress from confinement and maltreatment to mental health difficulties would be partially explained by an indirect effect through affect dysregulation and suppression (Hypothesis 3).

\section{Methods}

\section{Participants and Procedure}

Adolescent sample. Participants $(\mathrm{N}=809)$ were adolescents aged $12-18$ years old $(M=$ 15.66, $S D=1.37,56.7 \%$ identified female) who lived in Canada. Consistent with Canadian demographics (Statistics Canada, 2018), the sample was 74.3\% White, 5.1\% Asian (East and Southeast), 6.5\% Indigenous/Metis/First Nations, 1.9\% Black, and 8.6\% other ethnicities (e.g., Hispanic, mixed ethnicity). The sample also included adolescents from all provinces and territories with the exception of Nunavut. Based on self-report, $17.4 \%$ of adolescents had participated in some form of therapy in the past four months. More information about the sample can be found in (Craig, Ames et al., 2021).

Caregiver sample. Participants $(N=578,94.6 \%$ female $)$ were self-identified caregivers of adolescents (ages 12-18) who lived in Canada. Caregivers were aged 30 to $67(M=45.12, S D$ $=5.83$ ), and majority White (85.6\%), with 3.5\% Asian (East and Southeast), 5.9\% Indigenous/Metis/First Nations, 1.2\% Black, and 3.8\% other/mixed ethnicities. Most were biological mothers $(90.5 \%)$ or fathers $(3.1 \%)$, however, the sample also included adoptive mothers $(2.3 \%)$, stepmothers $(2.0 \%)$, and foster or kinship carers (2.2\%). Participants were recruited from all provinces and territories except for Nunavut.

Procedure. All participants were recruited through online advertisements on social media platforms (e.g., Facebook, Twitter, Instagram, Reddit) from June 17 to July 31, 2020. Informed consent was obtained from all participants and incentives were provided for participation (see 
[Craig, Ames et al., 2021] for details). The study protocol was approved by the authors' Institutional Research Boards.

\section{Measures}

The Ontario Child Health Study Scales (OCHS, Duncan et al., 2019) is a 52-item caregiver- or self-report measure of adolescent emotional and behavioral problems in the past four months. The current study examined the Conduct Disorder, Oppositional Defiant Disorder, Depression, and Anxiety, scales. Items were rated on a three-point Likert scale from 0 (never or not true) to 2 (often or very true). The current study combined the Conduct Disorder and Oppositional Defiant Disorder scales into an externalizing scale, and the depression and anxiety scales into an internalizing scale. Internal consistency for all scales was good for adolescent and caregiver report ( $\alpha=.68-.88$, and $\alpha=.76-.86$ respectively).

The COVID-19 Stress Scale (Findlay et al., 2020) is a self-report scale on COVID-19 related stressors, of which one item was used in the current study. Participants were asked how concerned they were about the impact of COVID-19 regarding "family stress from confinement" which was rated on a four-point Likert scale from 1 (Not at all) to 4 (Extremely).

The Conflicts Tactics Scale (CTS; Straus, 1979) is a widely used self-report questionnaire that assesses physical and psychological maltreatment in relationships. We utilized a modified version of the CTS (Moretti \& Craig, 2013) that measures adolescents' experiences of psychological and physical aggression in their relationships with their caregivers (e.g., "Done to you by your parent”). Consistent with past research, we assessed perpetration of aggression from caregiver to child as a maltreatment screener (Moretti \& Craig, 2013). Psychological and physical violence scales were each comprised of seven items rated on a 4-point Likert scale from 1 (Never) to 4 (Always). We used the mean score for each subscale in the analysis. The scales 
showed good reliability for adolescent and caregiver reports $(\alpha=.85-.90, \alpha=.78$, respectively).

The Affect Regulation Checklist (ARC; Moretti, 2003) is a 12-item self-report measure adapted from a scale of emotion regulation (Gross \& John, 2003). We focused on the 4-item affect dysregulation subscale (e.g., "It's very hard for me to calm down when I get upset") and the 5-item suppression subscale (e.g., "I try hard not to think about my feelings") scored on a 5point Likert Scale from 1 (Not like me) to 5 (A lot like me). Both scales showed good reliability in both adolescent and caregiver reports $(\alpha=.77-.79, \alpha=.79-.89$, respectively).

\section{Analysis}

To ensure our predictors were associated with our outcomes, correlations between our variables of interest were examined using SPSS 27.0 (IBM, 2020). All other analyses controlled for effects of age, gender, SES (parents only), and weeks since the beginning of the pandemic (i.e., number of weeks since March 1, 2020). Using Mplus 8.0 (Muthén \& Muthén, 2019), two path analysis models (i.e., one for adolescents, one for caregivers) were run in which family stress from confinement was set to have an indirect effect on adolescent internalizing and externalizing symptoms through maltreatment, affect dysregulation, and suppression. All models were estimated using full information maximum likelihood (FIML) with robust standard errors. FIML provides estimates of the variance-covariance matrix for all available data and includes individuals who are missing data on individual measures. Models were evaluated according to the most commonly used critical values for the fit indices, including a non-significant Chi-square $\left(X^{2}\right)$, a root mean square error of approximation (RMSEA) below .10 (Schermelleh-Engel et al., 2003), and comparative fit index (CFI) above .90 (Hu \& Bentler, 1999). Parameters were examined using standardized coefficients in Mplus (STDXY). Modification indices were examined to determine whether additional parameters were required in the models. 


\section{Results}

\section{Descriptive Statistics}

Adolescent sample. Descriptive data for the demographics and variables of interest can be found in Table 1. Physical maltreatment had a skew of 3.8 and kurtosis of 19.75. Except for physical maltreatment, all variables of interest had a skew and kurtosis within the acceptable range (George \& Mallery, 2010). A count variable of total psychological and physical maltreatment by caregivers was created by coding responses "often" or "always" as 1 and "none" or "rarely" as 0 and summed across items examine how many ways youth were experiencing maltreatment. Of the youth that completed the maltreatment measure $(n=718), 46 \%$ of youth reported experiencing at least one form of psychological maltreatment either "often" or "always" (see Table 2 for a break down of all items). More specifically, 12.5\% of all youth reported one form, $8.4 \%$ reported two forms, $7.5 \%$ reported three forms, $4.9 \%$ reported four forms, and $12.8 \%$ reported experiencing five or more forms of psychological abuse either "often" or "always". In terms of physical maltreatment, $7.9 \%$ of youth reported experiencing at least one form of physical maltreatment "often" or "always". More specifically, 5.3\% reported at least one form and $2.6 \%$ reported experiencing two or more forms "often" or "always."

Bivariate correlations (see Table 3) showed all variables of interest to be associated in the expected directions. Specifically, family stress from confinement was positively associated with both physical and psychological maltreatment. Family stress from confinement and both types of maltreatment were all positively associated with adolescents' affect dysregulation, suppression, and externalizing and internalizing symptoms.

Caregiver sample. Descriptive data for the demographics and variables of interest for the caregiver data can be found in Table 1. Except for physical maltreatment, all variables of 
interest had a skew and kurtosis in the acceptable range (George \& Mallery, 2010). As above, we examined maltreatment as reported by caregivers as a count variable across 7 physical and 9 psychological types of maltreatment. As shown in Table 2, 41.2\% of caregivers reported perpetrating at least one form of psychological maltreatment either "often" or "always". This included $13.2 \%$ of caregivers who reported one form, $9.7 \%$ reporting two forms, $5.3 \%$ reporting three forms, 5.1\% reporting four forms, and 7.8\% reporting five or more forms of psychological abuse either "often" or "always" in the last four months. For physical maltreatment, only $1.7 \%$ of caregivers reported at least one form of physical maltreatment either "often" or "always". Physical maltreatment had a skew of 5.54 and kurtosis of $42.84 .^{1}$

Caregiver reported correlations for all variables of interest can be found in Table 3. Similar to the youth sample, family stress from confinement, affect dysregulation, suppression, physical maltreatment, psychological maltreatment, internalizing symptoms, and externalizing symptoms were all significantly associated in the expected directions.

\section{Path Analysis Models}

Adolescent sample. Once both psychological and physical maltreatment were entered into the model, physical maltreatment did not predict either internalizing or externalizing symptoms and was thus removed from analyses. In the adolescent sample (See Figure 1 for parameters), the path model fit the data well $\chi^{2}(5)=9.25, p=.16$, CFI $=.99$, RMSEA $=.03$ $[95 \% \mathrm{CI} .00, .06]$. The model explains $42 \%$ of the variance in externalizing symptoms and $66 \%$ of the variance in internalizing symptoms. It also explained $28 \%$ of the variance in affect dysregulation and $12 \%$ of the variance in suppression. We examined indirect effects from family stress from confinement through affect regulation difficulties (i.e. affect dysregulation, affect suppression) to internalizing and externalizing symptoms, and then through a double indirect 
effect from family stress from confinement to psychological maltreatment to affect regulation difficulties (i.e. affect dysregulation, suppression) finally predicting internalizing and externalizing symptoms.

Family stress from confinement had an indirect effect through affect dysregulation on internalizing $(\beta=.14, p \leq .001)$ and externalizing symptoms $(\beta=.10, p<.001)$. In addition, family stress from confinement had an indirect effect through suppression on internalizing symptoms $(\beta=.03, p \leq .001)$ but not externalizing symptoms $(\beta=.01, p=.07)$. Family stress from confinement had an indirect effect through psychological maltreatment and affect dysregulation for internalizing $(\beta=.05, p \leq .001)$ and externalizing $(\beta=.04, p \leq .001)$. Family stress from confinement also had an indirect effect through psychological maltreatment and suppression for internalizing $(\beta=.03, p \leq .001)$ and externalizing $(\beta=.01, p=.04)$.

Caregiver sample. Once both psychological and physical maltreatment were entered into the model, physical maltreatment did not predict either internalizing or externalizing symptoms and was thus removed from analyses. In the caregiver reported model (see Figure 2), the model fit the data well $\chi^{2}(4)=4.97, p=.29, \mathrm{CFI}=.99, \mathrm{RMSEA}=.02[95 \%$ CI $.00, .07]$. The model explained $51 \%$ of variance of internalizing symptoms and $57 \%$ of the variance of externalizing symptoms. It also explained $18 \%$ of the variance in affect dysregulation and $13 \%$ of the variance in suppression. We examined the same indirect effects as laid out above.

Family stress from confinement had an indirect effect through affect dysregulation on internalizing symptoms $(\beta=.08, p \leq .001)$ and externalizing symptoms $(\beta=.09, p \leq .001)$. In contrast, family stress from confinement had an indirect effect through suppression on internalizing symptoms $(\beta=.03, p \leq .001)$ but did not have an indirect effect on externalizing symptoms $(\beta=$ $.01, p \equiv .27)$. Family stress from confinement had an indirect effect through psychological 
maltreatment and affect dysregulation for internalizing $(\beta=.02, p=.002)$ and externalizing $(\beta=$ $.02, p=.002)$. Family stress from confinement did not have an indirect effect through psychological maltreatment and suppression for internalizing $(\beta=.002, p=.06)$ or externalizing symptoms $(\beta=.001, p=.31)$.

\section{Discussion}

To our knowledge, the current study was the first to examine how family stress from confinement during the COVID-19 pandemic directly and indirectly relates to adolescents' mental health problems using both adolescent and caregiver samples. Our findings are three-fold. First, and consistent with early warnings regarding the effects of the pandemic on families (e.g., Coller \& Webber, 2020), we show that many Canadian adolescents and adults are reporting significant distress associated with being confined at home. More than $25 \%$ of youth and $11.3 \%$ of caregivers reported that confinement at home is resulting in "extreme" stress within their families. Indeed, in our previous work, we found that family stress from confinement was rated as the fourth most stressful impact of the COVID-19 pandemic, following worries about vulnerable community members, family members' health, and overloading the healthcare system (Craig, Ames et al., 2021). In the present study, we further found that family stress from confinement was positively associated with both psychological and physical maltreatment in adolescent and caregiver samples (consistent with Hypothesis 1). Second, our findings underscore concerning rates of child maltreatment during the pandemic. Over $40 \%$ of youth and caregivers endorsed maltreatment of adolescents in their homes, while 2-8\% of respondents reported physical maltreatment. Even though most of the psychological maltreatment was seemingly mild forms such as name-calling and swearing, these behaviors were significantly related to youths' mental health concerns (consistent with Hypothesis 2). It was unsurprising that 
physical maltreatment was no longer associated with mental health and affect regulation difficulties when entered simultaneously into the model with psychological maltreatment. Physical maltreatment often coincides with psychological maltreatment, as evident by their high correlation in the current and prior studies (e.g., Moretti \& Craig, 2013). Third and finally, our results corroborated a growing body of literature implicating affect dysregulation as a key mechanism that accounts for indirect effects of the association between family stress, psychological maltreatment, and adolescent mental health (Dvir et al., 2014). Our results build on the limited research of the indirect effect through of suppression, specifically finding it to be a significant partial indirect effect between family stress, psychological maltreatment and broad mental health concerns of youth and of internalizing (but not externalizing) concerns as reported by caregivers (Partially consistent with Hypothesis 3). Below, we explore each of these key findings in turn.

Considered alongside other studies of the impact of the pandemic on families, our results contribute to a growing and mixed picture. Previous studies, for instance, have found that parents are reporting an increased sense of closeness with their children (Gadermann et al., 2020) and that spending more time together as a family can buffer against the negative effects of the pandemic on adolescent mental health (Ellis et al., 2020). Conversely, other studies show that adults who are living with children under 18 years old are reporting greater stress, alcohol use, suicidal ideation, and concern about physical or emotional violence at home, relative to adults without children at home (Gadermann et al., 2020). These results paint a picture of both resilience and strain as families cope with the significant disruptions associated with the pandemic. Our results align with previous studies showing that being confined at home is a unique and salient source of stress for caregivers (Spinelli et al., 2020; Brooks et al., 2020), and 
extend this work by showing adolescents are keenly aware of this dynamic. Confinement-related challenges may include a lack of sufficient space and equipment for personal, work, and school activities for each family member, different daily routines, and difficulty balancing multiple roles that are now permeating the same time and space (e.g., parenting while working; completing school work while interacting with siblings), lack of access to important recreational activities, and a lack of restorative "down time" (Spinelli et al., 2020). These challenges are likely exacerbated for families who experience overcrowding, housing insecurity, or other difficulties in the home environment. Together, these effects seem to contribute to a significant rise in stress and mental health problems in Canadian families, affecting children and caregivers alike.

The robust literature pointing to elevated family stress associated with the COVID-19 pandemic (Gadermann et al., 2020) raises concern about child maltreatment, as stressed caregivers tend to use less sensitive, more coercive/controlling, and more punitive parenting strategies (Stith et al., 2009). Coupled with evidence that economic recessions are linked to increases in child abuse and neglect (Schneider et al., 2017), this emerging evidence has prompted warnings about rising child maltreatment that may go undetected while youth have less in-person contact with mandated reporters such as teachers, counsellors, and coaches (Campbell, 2020). Consistent with these concerns, national hotlines such as the Kids Help Phone have reported a $28 \%$ increase in calls that discuss physical abuse, relative to before the pandemic (Watson, 2020). In line with these concerns, our results show that high rates of child maltreatment are being reported both by caregivers and adolescents. The rates of psychological and physical maltreatment observed in these community samples mirror rates that were observed in a clinical sample of youth referred to an assessment or correctional facility prior to the pandemic (Craig \& Moretti, 2013). This is alarming, as correctional and clinical samples would 
be expected to be qualitatively and quantitatively distinct from community non-probability samples in terms of experiences of maltreatment. Our results are also consistent with past research showing psychological and physical maltreatment to be linked with a host of negative outcomes for adolescents, including decreased self-esteem, poor academic and occupational functioning, lower long-term wellbeing, and mental health problems (Cicchetti, 2016). Moreover, maltreatment perpetuated by a primary caregiver raises particular concerns as it damages a crucial attachment system that informs youths' growing sense of identity, selfefficacy, and relatedness. Youth who are maltreated by an attachment figure face the double challenge of coping with the trauma of the abuse while also not having access to a significant source of co-regulation. As such, the apparent rise in parental maltreatment of adolescents raises significant concerns for potential long-term sequelae for the present generation of youth in terms of their emotional, behavioral, and interpersonal wellbeing (Cuartas, 2020).

A final contribution of this study is that it implicates affect dysregulation and suppression as potential mechanisms by which family stress from confinement and maltreatment are associated with adolescent mental health concerns. Most studies examining affect regulation difficulties measure dysregulation as a trait or individual factor, rather examining the context in which it occurs (Gross \& Cassidy, 2019). Affect dysregulation can be seen as a reaction to an environmental trigger (e.g., increased stress at home) that precipitates an emotion (Gross, 1998), thereby explaining its indirect effect between family stress from confinement, maltreatment and adolescent mental health problems. In comparison, suppression can be viewed as an adaptive reaction to being in a perceived environment in which a youth feels unsafe to express their emotions to their attachment figures (Gross \& Cassidy, 2019). This is adaptive as expressing emotions in such an environment may result in further maltreatment or family stress as a 
caregiver is unable to cope with a youth's outburst (Gross \& Cassidy, 2019). It may also relieve the youth of the negative effects of feeling dysregulated in the short term. However, suppression of emotions has a paradoxical effect in which a youth may feel increased emotional intensity following their attempts to suppress their emotions (Hofmann et al., 2009). The implications of this affect dysregulation and suppression are increased anxiety and depression (Schäfer et al., 2017) and aggression (Kokkinos et al., 2017). In our study, suppression accounted for the indirect effect between the association between family stress from confinement on both internalizing and externalizing problems for youth report, but only to internalizing symptoms for caregiver report. One explanation may be that caregivers are unaware that youth are actively suppressing their emotions, as this is an internal process which may not be observable to caregivers. This may lead caregivers to overestimate the role of affect dysregulation and underestimate the role of suppression in their youth's functioning. Misunderstanding a youth's affect regulation process may be particularly problematic for parents who have youth with externalizing symptoms as it may be difficult for caregivers to recognize internalizing processes, such as suppression, in the face of behavior problems.

Given the likely necessity of continued periods of family confinement as the pandemic persists, effective mitigation of adolescent mental health concerns should focus on modifiable mechanisms that link family stress and maltreatment to psychopathology. Fortunately, numerous efficacious interventions target each of these processes. Parenting interventions that target the attachment relationship such as Connect Parent Group (e.g., Moretti et al., 2015) and Attachment Based Family Therapy (Diamond et al., 2016) may be helpful in repairing the negative effects of increased psychological maltreatment that is occurring in the attachment relationship during COVID-19 for adolescents. Attachment-based interventions have been shown to be efficacious 
in addressing parenting capacities in maltreating families with toddlers and young children (e.g., van der Asdonk et al., 2020) and there is evidence that attachment-based interventions may have similar effects in adolescents (e.g., Moretti et al., 2015). These interventions have also been shown to decrease youths' affect regulation difficulties (e.g., Moretti et al., 2015), indicating that repairing the attachment relationship may be effective in addressing the mediating factors to psychopathology. For those youth who experience continued affect regulation challenges, cognitive behavioral therapy and family and youth skills training in emotion regulation has been shown to improve ability to tolerate and effectively modulate difficult emotions (Suveg et al., 2009). COVID-19 has resulted in rapid expansion to online therapies, including attachmentbased therapies, however, there is continued concern with the efficacy and engagement of families in online therapy (Lebow, 2020). Evidence from this study suggests that increased family mental health is required both during and after the COVID-19 pandemic to mitigate the negative impacts from increased family stress.

Several limitations of the current study warrant consideration. First and foremost, this study presents cross-sectional data regarding the effects of the COVID-19 pandemic on family wellbeing, and thus cannot speak to the directionality of the effects. It is likely, for instance, that families in which youth are experiencing elevated internalizing and externalizing problems may experience proportionally higher stress from confinement because of the difficulty associated with witnessing and managing these concerns. In line with this, an Australian study showed that parents and children with pre-existing mental health concerns experienced more pandemicrelated stress and impaired family functioning since the onset of the pandemic (Westrupp et al., 2020). It is also difficult to examine mediation effects in a cross-sectional design, and thus we are careful to use the term 'indirect effects' throughout our paper. Second, while a strength of 
this work is the consideration of both youth and caregiver perspectives, our methods fall short of a true multi-informant approach where multiple parties provide ratings of the same family. Thus, we were unable to assess the degree to which caregivers and youth agree on the impact of the COVID-19 pandemic on their families, and whether such agreement is associated with increased family resilience. Third, while our sample demographics were broadly consistent with the gender and geographical distribution of Canadian youth (Statistics Canada, 2018), this sample was recruited via social media and cannot be considered representative of the Canadian population in dense cities. In particular, this sample was more likely to be White, and caregivers were found have slightly higher income/education, relative to the general population of Canadian adolescents. Further, our caregiver sample was largely female; having multiple genders in our caregiver sample would provide a more accurate understanding of family functioning. Families without consistent Internet access, who were precariously housed, or who do not use social media were unlikely to be represented in this sample. Given the non-probability sampling of the current study, it is also possible that the survey attracted adolescents and caregivers that were struggling with their mental health, which possibly explains why higher than expected maltreatment was found in the sample. Nevertheless, the associations between maltreatment, affect regulation difficulties, and youth mental health have been found in normative and highrisk samples (Moretti \& Craig, 2012) and thus this study adds to our understanding of these associations during COVID-19.

Bearing these limitations in mind, our study nonetheless contributes to our understanding of how Canadian families are faring during the COVID-19 pandemic and points to important directions for future work. First, many caregivers and youth urgently need support as they confront the significant challenges brought by the pandemic. Confinement at home has created 
significant stress and simultaneously reduced available outlets for stress relief. Families, in particular, have faced challenges given the disparate needs of household members who may be working or attending school virtually, caring for younger or older family members, and facing unique developmental challenges in responding to the pandemic. Beyond the previously mentioned attachment-based interventions, additional resources for families could include information on stress management, peer-led parenting support, and training in effective affect regulation. Additionally, these results highlight the need for ongoing monitoring of the populations' mental health as the pandemic subsides. The effects of child maltreatment are often, unfortunately, insidious and enduring. Not only would families benefit from immediate support, youth who experienced maltreatment during this stressful period may need long-term support as they navigate the sequelae. Given that some youth are faring well amidst the pandemic (Dvorsky et al., 2020), we also need to understand what contributes to resiliency in these challenging times. Longitudinal studies that follow adolescents throughout the COVID-19 pandemic and into a return to relatively normal life will be vital in assessing which youth will recover and which youth will require further support. 


\section{References}

Abaied, J. L., \& Rudolph, K. D. (2011). Maternal influences on youth responses to peer stress. Developmental Psychology, 47(6), 1776.

Bowlby, J. (1973). Separation: Anxiety and Anger: Attachment and Lose. 2. Hogarth.

Brooks, S. K., Webster, R. K., Smith, L. E., Woodland, L., Wessely, S., Greenberg, N., \& Rubin, G. J. (2020). The psychological impact of quarantine and how to reduce it: rapid review of the evidence. The Lancet, 395(10227), 912-920.

Cabrera-Hernández, F., \& Padilla-Romo, M. (2020). Hidden violence: How COVID-19 school closures reduced the reporting of child maltreatment. Latin American Economic Review, 29.

Campbell, A. M. (2020). An increasing risk of family violence during the Covid-19 pandemic:

Strengthening community collaborations to save lives. Forensic Science International: Reports, 2, 100089.

Cassidy, J. (1994). Emotion regulation: Influences of attachment relationships. Monographs of the Society for Research in Child Development, 59(2-3), 228-249.

Cicchetti, D. (2016). Socioemotional, personality, and biological development: Illustrations from a multilevel developmental psychopathology perspective on child maltreatment. Annual Review of Psychology, 67, 187-211.

Coller, R. J., \& Webber, S. (2020). COVID-19 and the well-being of children and families. Pediatrics, 146(4).

Collins, W. A., \& Laursen, B. (2004). Changing relationships, changing youth: Interpersonal contexts of adolescent development. Journal of Early Adolescence, 24, 55-62. 
Compier-de Block, L. H., Alink, L. R., Linting, M., van den Berg, L. J., Elzinga, B. M., Voorthuis, A., ... \& Bakermans-Kranenburg, M. J. (2017). Parent-child agreement on parentto-child maltreatment. Journal of Family Violence, 32(2), 207-217.

Craig, S.G, Ames, M.E., Bondi, B.C., \& Pepler, D.J. (2021) Adolescents amidst COVID-19: Rates of mental health problems, stress, substance use, and violence in the home. PsyArxiv

Cuartas, J. (2020). Heightened risk of child maltreatment amid the COVID-19 pandemic can exacerbate mental health problems for the next generation. Psychological Trauma: Theory, Research, Practice, and Policy, 12(S1), S195.

Diamond, G., Russon, J., \& Levy, S. (2016). Attachment-based family therapy: A review of the empirical support. Family Process, 55(3), 595-610.

Duncan, L., Georgiades, K., Wang, L., Comeau, J., Ferro, M. A., Van Lieshout, R. J., Szatmari, P., Bennett, K., MacMillan, H. L., Lipman, E. L., Janus, M., Kata, A., \& Boyle, M. H. (2019). The 2014 Ontario Child Health Study Emotional Behavioural Scales (OCHS-EBS) Part I: A Checklist for Dimensional Measurement of Selected DSM-5 Disorders. Canadian Journal of Psychiatry. Revue Canadienne de Psychiatrie, 64(6), 423-433.

Dvir, Y., Ford, J. D., Hill, M., \& Frazier, J. A. (2014). Childhood maltreatment, emotional dysregulation, and psychiatric comorbidities. Harvard Review of Psychiatry, 22(3), 149.

Dvorsky, M. R., Breaux, R., \& Becker, S. P. (2020). Finding ordinary magic in extraordinary times: child and adolescent resilience during the COVID-19 pandemic. European Child \& Adolescent Psychiatry, 1-3.

Ellis, W. E., Dumas, T. M., \& Forbes, L. M. (2020). Physically isolated but socially connected: 
Psychological adjustment and stress among adolescents during the initial COVID-19 crisis. Canadian Journal of Behavioural Science/Revue canadienne des sciences du comportement, 52(3), 177-187.

Fallon, B., Lefebvre, R., Filippelli, J., Joh-Carnella, N., Trocme, N., Carradine, J., \& Fluke, J. (2021). Major findings from the Ontario Incidence Study of Reported Child Abuse and Neglect 2018. Child Abuse \& Neglect, 111, 104778.

Findlay, L. C., Arim, R., \& Kohen, D. (2020). Understanding the perceived mental health of Canadians during the COVTD-19 pandemic. Health Reports, 31(4), 22-27.

Gadermann, A. C., Thomson, K. C., Richardson, C. G., Gagné, M., McAuliffe, C., Hirani, S., \& Jenkins, E. (2021). Examining the impacts of the COVID-19 pandemic on family mental health in Canada: findings from a national cross-sectional study. BMJ open, 11(1), e042871.

Galea, S., Merchant, R. M., \& Lurie, N. (2020). The mental health consequences of COVID-19 and physical distancing: The need for prevention and early intervention. JAMA Internal Medicine, 180(6), 817-818.

George, D., \& Mallery, M. (2010). SPSS for Windows Step by Step: A Simple Guide and Reference, 17.0 update (10a ed.) Boston: Pearson.

Gross, J. J., \& John, O. P. (2003). Individual differences in two emotion regulation processes: implications for affect, relationships, and well-being. Journal of Personality and Social Psychology, 85(2), 348-362.

Gross, J. T., \& Cassidy, J. (2019). Expressive suppression of negative emotions in children and adolescents: Theory, data, and a guide for future research. Developmental Psychology, 
55(9), 1938.

Gruhn, M. A., \& Compas, B. E. (2020). Effects of maltreatment on coping and emotion regulation in childhood and adolescence: A meta-analytic review. Child Abuse \& Neglect, $103,104446$.

Hawley, K. M., \& Weisz, J. R. (2003). Child, parent and therapist (dis) agreement on target problems in outpatient therapy: The therapist's dilemma and its implications. Journal of Consulting and Clinical Psychology, 71(1), 62.

Hofmann, S. G., Heering, S., Sawyer, A. T., \& Asnaani, A. (2009). How to handle anxiety: The effects of reappraisal, acceptance, and suppression strategies on anxious arousal. Behavior Research and Therapy, 47, 389-394.

Hong, F., Tarullo, A. R., Mercurio, A. E., Liu, S., Cai, Q., \& Malley-Morrison, K. (2018). Childhood maltreatment and perceived stress in young adults: The role of emotion regulation strategies, self-efficacy, and resilience. Child Abuse \& Neglect, 86, 136-146.

Hu, L. T., \& Bentler, P. M. (1999). Cutoff criteria for fit indexes in covariance structure analysis: Conventional criteria versus new alternatives. Structural Equation Modeling: A Multidisciplinary Journal, 6(1), 1-55.

IBM Corp. (2020). IBM SPSS Statistics for Windows, Version 27.0.

Kim, J., \& Cicchetti, D. (2010). Longitudinal pathways linking child maltreatment, emotion regulation, peer relations, and psychopathology. Journal of Child Psychology and Psychiatry, 51(6), 706-716.

Kokkinos, C. M., \& Voulgaridou, I. (2017). Relational and cyber aggression among adolescents: 
Personality and emotion regulation as moderators. Computers in Human Behavior, 68, 528537.

Lebow J. L. (2020). Family in the Age of COVID-19. Family process, 59(2), 309-312.

Levitt, M. J., Guacci-Franco, N., \& Levitt, J. L. (1993). Convoys of social support in childhood and early adolescence: Structure and function. Developmental Psychology, 29, 811-818.

Moretti, M. M. (2003). Affect regulation checklist. Unpublished measure and data. British Columbia, Canada: Simon Fraser University.

Moretti, M. M., Bartolo, T., Craig, S., Slaney, K., \& Odgers, C. (2014). Gender and the transmission of risk: A prospective study of adolescent girls exposed to maternal versus paternal interparental violence. Journal of Research on Adolescence, 24(1), 80-92.

Moretti, M. M., \& Craig, S. G. (2013). Maternal versus paternal physical and emotional abuse, affect regulation and risk for depression from adolescence to early adulthood. Child Abuse and Neglect, 37(1), 4-13.

Moretti, M. M., Obsuth, I., Craig, S. G., \& Bartolo, T. (2015). An attachment-based intervention for parents of adolescents at risk: mechanisms of change. Attachment \& Human Development, 17(2), 119-135.

Morris, A. S., Silk, J. S., Steinberg, L., Myers, S. S., \& Robinson, L. R. (2007). The role of the family context in the development of emotion regulation. Social Development, 16, 361-388.

Muthén, L., \& Muthén, B. (2019). Mplus. The comprehensive modelling program for applied researchers: User's Guide, 5.

Rescorla, L. A., Ginzburg, S., Achenbach, T. M., Ivanova, M. Y., Almqvist, F., Begovac, I., ... \& 
Verhulst, F. C. (2013). Cross-informant agreement between parent-reported and adolescent self-reported problems in 25 societies. Journal of Clinical Child \& Adolescent Psychology, 42(2), 262-273.

Salbach-Andrae, H., Klinkowski, N., Lenz, K., \& Lehmkuhl, U. (2009). Agreement between youth-reported and parent-reported psychopathology in a referred sample. European Child \& Adolescent Psychiatry, 18(3), 136-143.

Schermelleh-Engel, K., Moosbrugger, H., \& Müller, H. (2003). Evaluating the fit of structural equation models: Tests of significance and descriptive goodness-of-fit measures. Methods of Psychological Research Online, 8(2), 23-74.

Schneider, W., Waldfogel, J., \& Brooks-Gunn, J. (2017). The Great Recession and risk for child abuse and neglect. Children and Youth Services Review, 72, 71-81.

Schäfer, L., Hübner, C., Carus, T., Herbig, B., Seyfried, F., Kaiser, S., ... \& Hilbert, A. (2017). Identifying prebariatric subtypes based on temperament traits, emotion dysregulation, and disinhibited eating: A latent profile analysis. International Journal of Eating Disorders, 50(10), 1172-1182.

Sistad, R. E., Simons, R. M., Mojallal, M., \& Simons, J. S. (2021). The indirect effect from childhood maltreatment to PTSD symptoms via thought suppression and cognitive reappraisal. Child Abuse \& Neglect, 114, 104939.

Spinelli, M., Lionetti, F., Pastore, M., \& Fasolo, M. (2020). Parents' stress and children's psychological problems in families facing the COVID-19 outbreak in Italy. Frontiers in Psychology, 11, 1713. 
Statistics Canada (2018, February 7). A portrait of Canadian youth.

https://www150.statcan.gc.ca/n1/pub/11-631-x/11-631-x2018001-eng.htm

Stevens, F. L. (2014). Affect Regulation Styles in Avoidant and Anxious Attachment. Individual Differences Research, 12(3), 123-130.

Stith, S. M., Liu, T., Davies, L. C., Boykin, E. L., Alder, M. C., Harris, J. M., ... \& Dees, J. E. M. E. G. (2009). Risk factors in child maltreatment: A meta-analytic review of the literature. Aggression and Violent Behavior, 14(1), 13-29.

Straus, M. A. (1979). Measuring intrafamily conflict and violence: The conflict tactics (CT) scales. Journal of Marriage and the Family, 75-88.

Suveg, C., Sood, E., Comer, J. S., \& Kendall, P. C. (2009). Changes in emotion regulation following cognitive-behavioral therapy for anxious youth. Journal of Clinical Child \& Adolescent Psychology, 38(3), 390-401.

Thompson, R. (2019). Emotion dysregulation: A theme in search of definition. Development and Psychopathology, 31(3), 805-815.

Trocmé, N. (2010). Canadian incidence study of reported child abuse and neglect, 2008: Major findings. Public Health Agency of Canada.

Troy, A. S., \& Mauss, I. B. (2011). Resilience in the face of stress: Emotion regulation ability as a protective factor. In S. Southwick, D. Charney, M. Friedman, \& B. Litz (Eds.), Resilience to stress (pp. 30 - 44). Cambridge, England: Cambridge University Press.

van der Asdonk, S., de Haan, W. D., van Berkel, S. R., van IJzendoorn, M. H., Rippe, R. C., Schuengel, C., ... \& Alink, L. R. (2020). Effectiveness of an attachment-based intervention 
for the assessment of parenting capacities in maltreating families: A randomized controlled trial. Infant Mental Health Journal, 41(6), 821-835.

Watson, B. (2020). Kids Help Phone reports spike in calls from B.C. children during COVID-19 pandemic. CBC news. https://www.cbc.ca/news/canada/british-columbia/kids-help-phone-bc-1.5648891

Westrupp, E., Bennett, C., Berkowitz, T. S., Youssef, G., Toumbourou, J., Tucker, R., ... \& Sciberras, E. (2020). Child, parent, and family mental health and functioning in Australia during COVID-19: Comparison to pre-pandemic data. 
Table 1. Descriptive Table for Adolescent and Caregiver Sample Demographics

\begin{tabular}{|c|c|c|c|c|}
\hline \multirow[b]{2}{*}{ Scale } & \multicolumn{2}{|c|}{ Adolescent report } & \multicolumn{2}{|c|}{ Caregiver report } \\
\hline & $\% / M(S D)$ & Range & $\% / M(S D)$ & Range \\
\hline Youth Age & $15.67(1.37)$ & $12-18$ & $14.63(1.77)$ & $12-18$ \\
\hline Caregiver Age & & & $45.12(5.83)$ & $30-67$ \\
\hline \multicolumn{5}{|l|}{ Youth Gender } \\
\hline Female & $56.2 \%$ & & $55.2 \%$ & \\
\hline Male & $38.7 \%$ & & $43.9 \%$ & \\
\hline $\begin{array}{l}\text { Trans/ Nonbinary } \\
\text { individuals }\end{array}$ & $5.1 \%$ & & $0.9 \%$ & \\
\hline \multicolumn{5}{|l|}{ Caregiver Gender } \\
\hline Female & & & $94.6 \%$ & \\
\hline Male & & & $5.0 \%$ & \\
\hline Trans/ Nonbinary & & & $0.3 \%$ & \\
\hline \multicolumn{5}{|l|}{ Individual } \\
\hline \multicolumn{5}{|l|}{ Ethnicity } \\
\hline Caucasian & $74.1 \%$ & & $85.6 \%$ & \\
\hline $\begin{array}{l}\text { Asian (East and } \\
\text { Southeast) }\end{array}$ & $8.7 \%$ & & $3.5 \%$ & \\
\hline $\begin{array}{l}\text { Indigenous/Metis/First } \\
\text { Nations }\end{array}$ & $6.7 \%$ & & $5.9 \%$ & \\
\hline Black & $2 \%$ & & $1.2 \%$ & \\
\hline Other/Mixed & $8.6 \%$ & & $2.8 \%$ & \\
\hline \multicolumn{5}{|l|}{ Lives with } \\
\hline Parents & $95.2 \%$ & & & \\
\hline Foster/ Group/ Other & $4.9 \%$ & & & \\
\hline \multicolumn{5}{|l|}{ Family composition } \\
\hline Two caregivers & $69.7 \%$ & & $72.8 \%$ & \\
\hline One caregiver & $22.1 \%$ & & $21.6 \%$ & \\
\hline Other & $8.2 \%$ & & $5.5 \%$ & \\
\hline \multicolumn{5}{|l|}{$\begin{array}{l}\text { School attendance in } \\
\text { spring }\end{array}$} \\
\hline Online & $83.8 \%$ & & $90.1 \%$ & \\
\hline $\begin{array}{l}\text { Mixed (online and in } \\
\text { person) }\end{array}$ & $7.5 \%$ & & N/A & \\
\hline In person & $2.0 \%$ & & $3.6 \%$ & \\
\hline None & $6.7 \%$ & & $6.2 \%$ & \\
\hline $\begin{array}{l}\text { Psychological } \\
\text { Maltreatment }\end{array}$ & $1.59(.62)$ & $1.00-4.00$ & $1.33(.28)$ & $1-2.67$ \\
\hline Physical Maltreatment & $1.12(.29)$ & $1-3.71$ & $1.06(.16)$ & $1-2.71$ \\
\hline $\begin{array}{l}\text { Family Stress due to } \\
\text { Confinement }\end{array}$ & $2.64(1.05)$ & $1.00-4.00$ & $2.37(.88)$ & $1.00-4.00$ \\
\hline Affect Dysregulation & $12.05(4.83)$ & $4.00-20.00$ & $10.39(4.81)$ & $4.00-20.00$ \\
\hline Internalizing Symptoms & $15.63(7.60)$ & $.00-30.00$ & $9.79(6.29)$ & $.00-28.00$ \\
\hline Externalizing Symptoms & $6.28(4.14)$ & $.00-26.00$ & $5.57(4.51)$ & $.00-25.00$ \\
\hline
\end{tabular}


Table 2. Maltreatment Items by Scale

\begin{tabular}{|c|c|c|c|c|c|c|}
\hline \multirow[b]{2}{*}{ Scale } & \multicolumn{3}{|c|}{ Youth report } & \multicolumn{3}{|c|}{ Caregiver report } \\
\hline & $\begin{array}{l}\text { Never } \\
\mathrm{N}(\%)\end{array}$ & $\begin{array}{l}\text { Rarely } \\
\mathrm{N}(\%)\end{array}$ & $\begin{array}{l}\text { Often/ } \\
\text { Always } \\
\mathrm{N}(\%)\end{array}$ & $\begin{array}{l}\text { Never } \\
\mathrm{N}(\%)\end{array}$ & $\begin{array}{l}\text { Rarely } \\
\mathrm{N}(\%)\end{array}$ & $\begin{array}{l}\text { Often/ } \\
\text { Always } \\
\text { N (\%) }\end{array}$ \\
\hline \multicolumn{7}{|l|}{ Physical } \\
\hline Threw something that could hurt & $\begin{array}{l}634 \\
(88.3 \%)\end{array}$ & $\begin{array}{l}69 \\
(9.6 \%)\end{array}$ & $\begin{array}{l}15 \\
(2.1 \%)\end{array}$ & $\begin{array}{l}477 \\
(96.8 \%)\end{array}$ & $\begin{array}{l}15 \\
(3.0 \%)\end{array}$ & $<1 \%$ \\
\hline Pushed or shoved & $\begin{array}{l}617 \\
(86.1 \%)\end{array}$ & $\begin{array}{l}85 \\
(11.9 \%)\end{array}$ & $\begin{array}{l}15 \\
(2.1 \%)\end{array}$ & $\begin{array}{l}463 \\
(93.9 \%)\end{array}$ & $\begin{array}{l}29 \\
(5.9 \%)\end{array}$ & $<1 \%$ \\
\hline $\begin{array}{l}\text { Punched or hit with something that } \\
\text { could hurt }\end{array}$ & $\begin{array}{l}659 \\
(91.9 \%)\end{array}$ & $\begin{array}{l}47 \\
(6.6 \%)\end{array}$ & $\begin{array}{l}11 \\
(1.6 \%)\end{array}$ & $\begin{array}{l}477 \\
(96.8 \%)\end{array}$ & $\begin{array}{l}13 \\
(2.6 \%)\end{array}$ & $<1 \%$ \\
\hline Beat up & $\begin{array}{l}688 \\
(96.1 \%)\end{array}$ & $\begin{array}{l}25 \\
(3.5 \%)\end{array}$ & $<1 \%$ & $\begin{array}{l}484 \\
(98.2 \%)\end{array}$ & $<2 \%$ & $<1 \%$ \\
\hline Grabbed & $\begin{array}{l}593 \\
(82.7 \%)\end{array}$ & $\begin{array}{l}93 \\
(13.0 \%)\end{array}$ & $\begin{array}{l}31 \\
(4.3 \%)\end{array}$ & $\begin{array}{l}415 \\
(84.3 \%)\end{array}$ & $\begin{array}{l}69 \\
(14 \%)\end{array}$ & $\begin{array}{l}8 \\
(1.6 \%)\end{array}$ \\
\hline Slapped & $\begin{array}{l}632 \\
(88.3 \%)\end{array}$ & $\begin{array}{l}67 \\
(9.4 \%)\end{array}$ & $\begin{array}{l}17 \\
(2.4 \%)\end{array}$ & $\begin{array}{l}471 \\
(95.9 \%)\end{array}$ & $\begin{array}{l}18 \\
(3.7 \%)\end{array}$ & $<1 \%$ \\
\hline Kicked & $\begin{array}{l}685 \\
(95.5 \%)\end{array}$ & $\begin{array}{l}28 \\
(3.9 \%)\end{array}$ & $<1 \%$ & $\begin{array}{l}451 \\
(98 \%)\end{array}$ & $<2 \%$ & $<1 \%$ \\
\hline \multicolumn{7}{|l|}{ Psychological } \\
\hline Insulted or swore at person & $\begin{array}{l}320 \\
(44.6 \%)\end{array}$ & $\begin{array}{l}228 \\
(31.8 \%)\end{array}$ & $\begin{array}{l}170 \\
(23.7 \%)\end{array}$ & $\begin{array}{l}284 \\
(57.6 \%)\end{array}$ & $\begin{array}{l}182 \\
(36.9 \%)\end{array}$ & $\begin{array}{l}27 \\
(5.5 \%)\end{array}$ \\
\hline $\begin{array}{l}\text { Called fat or ugly (insulted physical } \\
\text { appearance) }\end{array}$ & $\begin{array}{l}540 \\
(75.3 \%)\end{array}$ & $\begin{array}{l}103 \\
(14.4 \%)\end{array}$ & $\begin{array}{l}95 \\
(13.2 \%)\end{array}$ & $\begin{array}{l}478 \\
(97 \%)\end{array}$ & $\begin{array}{l}14 \\
(2.8 \%)\end{array}$ & $<1 \%$ \\
\hline $\begin{array}{l}\text { Destroyed something belonging to } \\
\text { other person }\end{array}$ & $\begin{array}{l}351 \\
(90.8 \%)\end{array}$ & $\begin{array}{l}49 \\
(6.8 \%)\end{array}$ & $\begin{array}{l}17 \\
(2.4 \%)\end{array}$ & $\begin{array}{l}474 \\
(96.1 \%)\end{array}$ & $\begin{array}{l}17 \\
(3.4 \%)\end{array}$ & $<1 \%$ \\
\hline $\begin{array}{l}\text { Stomped out of the room, house, or } \\
\text { yard during a disagreement }\end{array}$ & $\begin{array}{l}406 \\
(56.6 \%)\end{array}$ & $\begin{array}{l}167 \\
(23.3 \%)\end{array}$ & $\begin{array}{l}144 \\
(20.1 \%)\end{array}$ & $\begin{array}{l}248 \\
(50.4 \%)\end{array}$ & $\begin{array}{l}219 \\
(44.5 \%)\end{array}$ & $\begin{array}{l}25 \\
(5.1 \%)\end{array}$ \\
\hline Said something to spite & $\begin{array}{l}386 \\
(53.9 \%)\end{array}$ & $\begin{array}{l}183 \\
(25.6 \%)\end{array}$ & $\begin{array}{l}147 \\
(20.5 \%)\end{array}$ & $\begin{array}{l}322 \\
(65.6 \%)\end{array}$ & $\begin{array}{l}155 \\
(31.6 \%)\end{array}$ & $\begin{array}{l}14 \\
(2.8 \%)\end{array}$ \\
\hline Threatened to hit or throw something & $\begin{array}{l}590 \\
(82.3 \%)\end{array}$ & $\begin{array}{l}80 \\
(11.2 \%)\end{array}$ & $\begin{array}{l}47 \\
(6.6 \%)\end{array}$ & $\begin{array}{l}451 \\
(91.9 \%)\end{array}$ & $\begin{array}{l}36 \\
(7.3 \%)\end{array}$ & $<1 \%$ \\
\hline Shouted or yelled & $\begin{array}{l}189 \\
(26.4 \%)\end{array}$ & $\begin{array}{l}245 \\
(34.2 \%)\end{array}$ & $\begin{array}{l}283 \\
(39.4 \%)\end{array}$ & $\begin{array}{l}98 \\
(20.0 \%)\end{array}$ & $\begin{array}{l}275 \\
(56.0 \%)\end{array}$ & $\begin{array}{l}118 \\
(24.1 \%)\end{array}$ \\
\hline Said something to hurt and humiliate & $\begin{array}{l}422 \\
(58.9 \%)\end{array}$ & $\begin{array}{l}161 \\
(22.5 \%)\end{array}$ & $\begin{array}{l}134 \\
(18.6 \%)\end{array}$ & $\begin{array}{l}383 \\
(78.0 \%)\end{array}$ & $\begin{array}{l}97 \\
(19.8 \%)\end{array}$ & $\begin{array}{l}11 \\
(2.2 \%)\end{array}$ \\
\hline $\begin{array}{l}\text { Threatened to abandon or kick out of } \\
\text { the house }\end{array}$ & $\begin{array}{l}589 \\
(82.1 \%)\end{array}$ & $\begin{array}{l}68 \\
(9.5 \%)\end{array}$ & $\begin{array}{l}60 \\
(8.3 \%)\end{array}$ & $\begin{array}{l}442 \\
(90.4 \%)\end{array}$ & $\begin{array}{l}43 \\
(8.8 \%)\end{array}$ & $<1 \%$ \\
\hline
\end{tabular}


Table 3. Correlation Table for all Variables of Interest

\begin{tabular}{|c|c|c|c|c|c|c|c|c|c|}
\hline & 1 & 2 & 3 & 4 & 5 & 6 & 7 & 8 & 9 \\
\hline $\begin{array}{l}\text { 1. Psychological } \\
\text { Maltreatment }\end{array}$ & & $.56 * * *$ & $.17 * * *$ & $.37 * * *$ & $.18 * * *$ & $.26 * * *$ & $.49 * * *$ & .03 & -.07 \\
\hline $\begin{array}{l}\text { 2. Physical } \\
\text { Maltreatment }\end{array}$ & $.63 * * *$ & & $.09 *$ & $.21 * * *$ & $.13 * * *$ & $.13 * *$ & $.32 * * *$ & -.05 & -.12 \\
\hline $\begin{array}{l}\text { 3. Family stress } \\
\text { from } \\
\text { confinement }\end{array}$ & $.30 * * *$ & $.13 * * *$ & & $.24 * * *$ & $.29 * * *$ & $.37 * * *$ & $.33 * * *$ & .04 & -.05 \\
\hline $\begin{array}{l}\text { 4. Affect } \\
\text { Dysregulation }\end{array}$ & $.38 * * *$ & $.21 * * *$ & $.37 * * *$ & & $.41 * * *$ & $.63 * * *$ & $.69 * * *$ & .03 & -.04 \\
\hline $\begin{array}{l}\text { 5. Affect } \\
\text { Suppression }\end{array}$ & $.30 * * *$ & $.15^{* * *}$ & $.21 * * *$ & $.45^{* * *}$ & & $.39 * * *$ & $.36 * * *$ & -.01 & .05 \\
\hline $\begin{array}{l}\text { 6. Internalizing } \\
\text { symptoms }\end{array}$ & $.46^{* * *}$ & $.26^{* * *}$ & $.41 * * *$ & $.75^{* * *}$ & $.53 * * *$ & & $.55^{* * *}$ & .06 & .06 \\
\hline $\begin{array}{l}\text { 7. Externalizing } \\
\text { symptoms }\end{array}$ & $.49 * * *$ & $.35^{* * *}$ & $.25 * * *$ & $.54 * * *$ & $.35 * * *$ & $.54 * * *$ & & .04 & -.07 \\
\hline $\begin{array}{l}\text { 8. Weeks since } \\
\text { beginning of } \\
\text { pandemic }\end{array}$ & $.08 *$ & 0.03 & $.13 * * *$ & $.14^{* * *}$ & -.01 & $.07 *$ & 0.06 & & \\
\hline 9. Youth Age & -.04 & $-.12 * *$ & .00 & .06 & .01 & $.09 * *$ & -0.01 & $-0.09 *$ & \\
\hline
\end{tabular}

Note: $* p<.05 * * p<.01, * * * p \leq .001$, bottom left is youth report, top right is caregiver report 
Figure 1. Youth Report Path Analysis Model for Internalizing and Externalizing Symptoms.

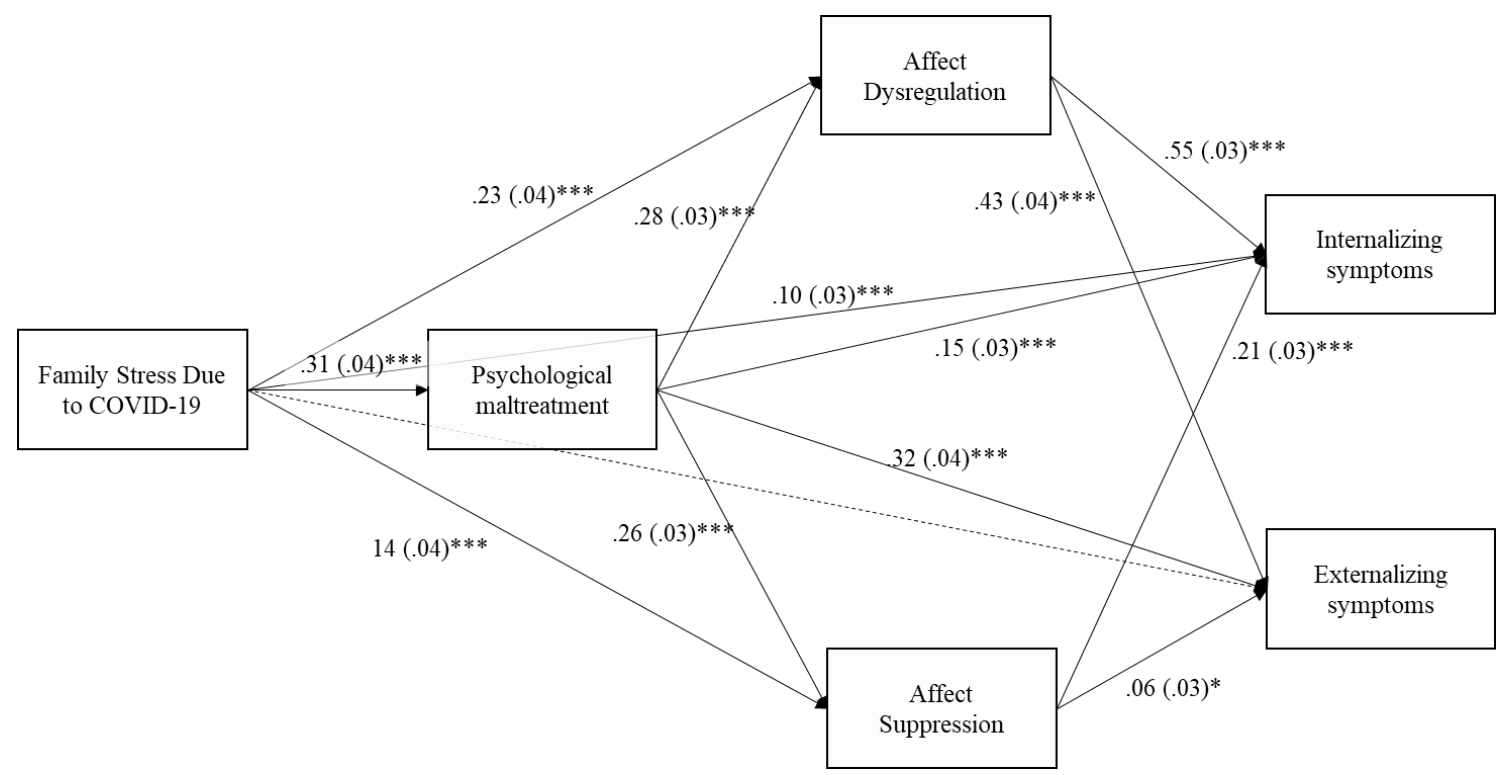

Note. $* p<.05, * * * p \leq .001$, dotted lines represent non-significant paths; model controls for youth age, gender, and weeks since beginning of the pandemic 
Figure 2. Caregiver Report Path Analysis Model for Internalizing and Externalizing Symptoms.

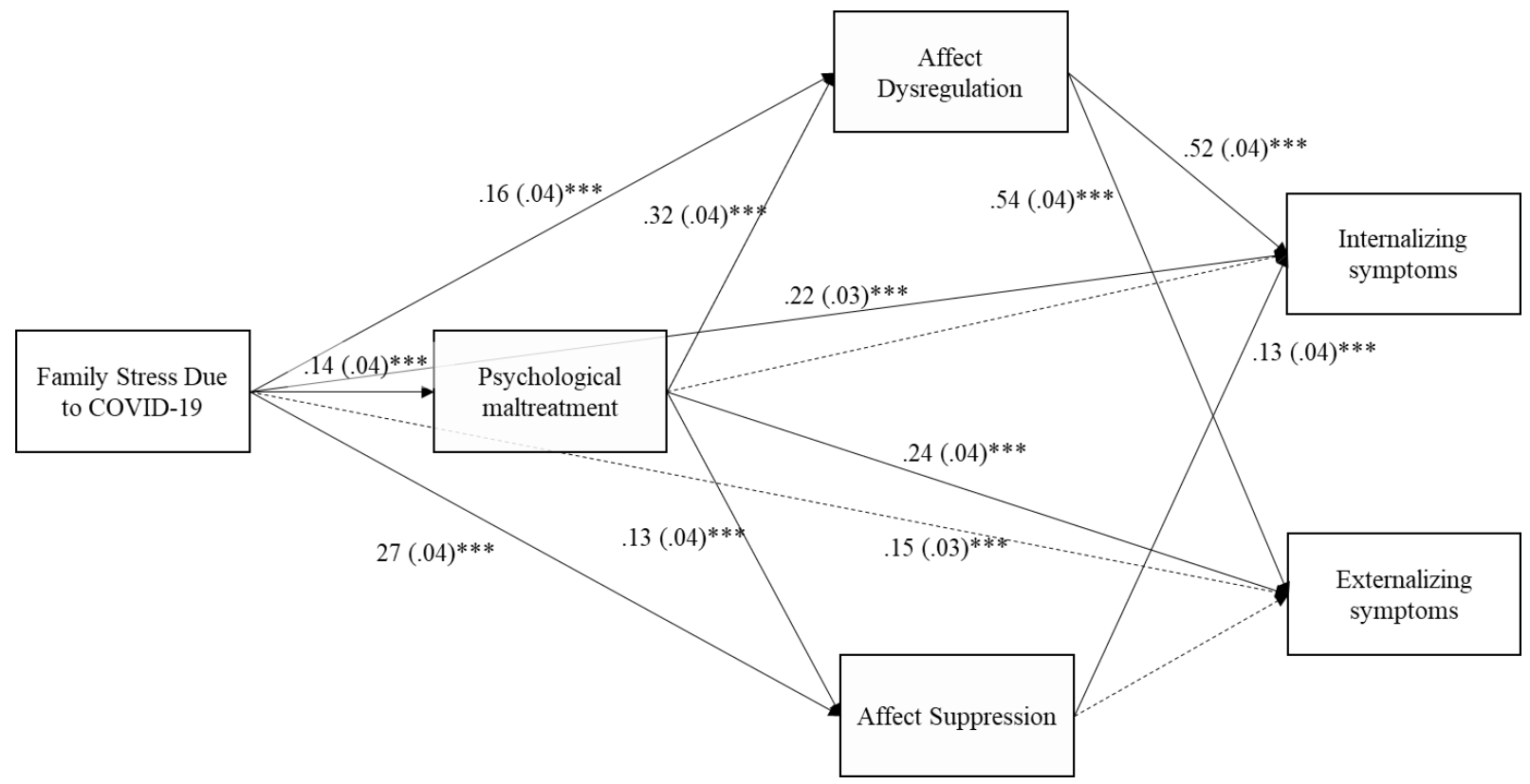

Note. $* * * p \leq .001$, dotted lines represent non-significant paths; model controls for parent age and gender, youth age and gender, SES, and weeks since beginning of the pandemic. 